\title{
Biomarkers of Oxidative Stress and Endothelial Dysfunction After Tourniquet Release in Children
}

\author{
I. BUDIC ${ }^{1}$, D. PAVLOVIC ${ }^{2}$, G. KOCIC ${ }^{2}$, T. CVETKOVIC ${ }^{2}$, D. SIMIC ${ }^{3}$, J. BASIC , $^{2}$ \\ D. ZIVANOVIC ${ }^{4}$
}

${ }^{1}$ Centre for Anesthesiology and Reanimatology, Clinical Centre Nis, Medical Faculty, University of Nis, Serbia, ${ }^{2}$ Institute of Biochemistry, Medical Faculty, University of Nis, Serbia, ${ }^{3}$ University Children's Hospital, Medical Faculty, University of Belgrade, Serbia, ${ }^{4}$ Clinic for Pediatric Surgery and Orthopedics, Clinical Centre Nis, Medical Faculty, University of Nis, Serbia

Received December 8, 2010

Accepted February 16, 2011

On-line July 19, 2011

\section{Summary}

Pneumatic tourniquets are widely used in pediatric extremity surgery to provide a bloodless field and facilitate dissection. This prospective study was carried out to examine possible effect of different anesthesia techniques on oxidative stress and endothelial dysfunction connected with ischemia-reperfusion injury during extremity operations at children's age. Patients were randomized into three groups of 15 patients each: general inhalational anesthesia with sevoflurane (group S), total intravenous anesthesia with propofol (group T) and regional anesthesia (group R). Venous blood samples for determination of the malondialdehyde in plasma and erythrocytes, protein carbonyl groups concentration as well as plasma nitrites and nitrates level and xanthine oxidase activity were obtained at four time points: before peripheral nerve block and induction of general anesthesia (baseline), 1 min before tourniquet release, 5 and $20 \mathrm{~min}$ after tourniquet release. This study demonstrates that total intravenous anesthesia with propofol and regional anesthesia techniques provide better antioxidant defense and reduce endothelial dysfunction than general inhalational anesthesia with sevoflurane during tourniquet application in pediatric extremity surgery.

\section{Key words}

Tourniquet $\bullet$ Child $\bullet$ Oxidative stress $\bullet$ Endothelium

\section{Corresponding author}

Ivana Budic, Department of Anesthesia, Clinic for Pediatric Surgery and Orthopedics, Centre for Anesthesiology and Reanimatology, Clinical Centre Nis, Bulevar Dr Zorana Djindjica 48, 18000 Nis, Serbia. E-mail: ibudic@open.telekom.rs

\section{Introduction}

During orthopedic surgery tourniquets are commonly applied to reduce blood loss and obtain a clearer surgical field. When the tourniquet is released, excessive formation of free radicals follows during reperfusion and oxygenation. Free radicals induce endothelial dysfunction and infiltration of neutrophils, which are responsible for ischemia-reperfusion (I/R) injury (Gourdin et al. 2009). Nitric oxide (NO) can demonstrate either protective or cytotoxic effects during reperfusion injury. The nicotinamide adenine dinucleotide phosphate (NADPH2) oxidase of the neutrophils, xanthine oxidase (XO) and the dysfunctioning of mitochondrial oxidative phosphorilation are the principal producers of oxygenfree radicals (ROS), such as superoxide anion $\left(\mathrm{O}_{2}^{-}\right)$, hydrogen peroxide $\left(\mathrm{H}_{2} \mathrm{O}_{2}\right)$ and hydroxyl radical $(\mathrm{OH} \cdot)$, at the time of reperfusion. The $\mathrm{O}_{2}{ }^{-}$and $\mathrm{NO}$ react to produce a reactive nitrogen species peroxynitrite $\left(\mathrm{ONOO}^{-}\right)$. On the other hand, the loss of output of NO explains the loss of the dependent endothelial vasodilatation on the posthypoxic endothelium. It seems that orthopedic surgery with tourniquet is a good human model for excessive production of oxidants and anesthetics with anti-oxidant properties or free radical scavenging activity could offer considerable protection and benefits in this setting (Arnaoutoglou et al. 2007). In adults various comorbid conditions could overlap and contribute to oxidative stress and endothelial dysfunction. Thus, 
studies conducted in children may provide more accurate results and improve our daily practice in a manner to find best choice of anesthetics for our patients.

Propofol appears to inhibit lipid peroxidation secondary to oxidative stress in "in vitro" studies (Tsuchiya et al. 2010) and to reduce lipid peroxidation during skeletal muscle ischemia-reperfusion injury (Arnaoutoglou et al. 2007). Many studies have shown the protective effects of sevoflurane and other halogenated anesthetics on the myocardium after ischemia and more specifically the limitation of myocardial dysfunction and necrosis in the reperfusion phase (Zaugg et al. 2003). Some studies reported less hemodynamic and metabolic changes related to tourniquet application in patients undergoing regional anesthesia compared with general anesthesia (Saricaoglu et al. 2005). Furthermore, local anesthetics inhibit migration, enzyme release and $\mathrm{O}_{2}{ }^{-}$. generation of polymorphonuclear leukocytes (Welters et al. 2001). To our knowledge, its effects on skeletal muscle I/R injury in children have not been examined.

We designed a study to investigate possible effect of different anesthesia techniques on oxidative stress and endothelial dysfunction connected with $\mathrm{I} / \mathrm{R}$ injury during extremity operations at children's age.

\section{Methods}

After obtaining the ethical committee approval (No. 01-1674, March 13 2008, according to the Article 37 of the Medical School in Nis Ethical Committee Regulation) and written informed consent from the parents, we studied 45 patients ASA I or II, 8 to 17 years of age, undergoing orthopedic procedures that required bloodless limb surgery. Children were randomized to sevoflurane $(n=15)$, propofol $(n=15)$ or peripheral nerve block ( $n=15)$ group. All patients were premedicated with midazolam. In the sevoflurane group (group S) general anesthesia was induced with thiopental $(5 \mathrm{mg} / \mathrm{kg})$ with alfentanyl $(25 \mathrm{mcg} / \mathrm{kg})$ and maintained with inhalation of sevoflurane (3-4 vol \%). In the propofol group (group T), anaesthesia was induced with propofol followed by continuous infusion of propofol at a rate of $10 \mathrm{mg} / \mathrm{kg} / \mathrm{h}$, reducing to 8 and $6 \mathrm{mg} / \mathrm{kg} / \mathrm{h}$, respectively, at 10 minutes interval. The maintenance dose was adjusted to clinical signs and anticipated demand, according to total intravenous anesthesia concept (TIVA). Atracurium $(0.6 \mathrm{mg} / \mathrm{kg})$ was given to facilitate tracheal intubation in sevoflurane and propofol group and the lungs were ventilated with $65 \%$ nitrogen in oxygen. Rescue analgesia was provided by single bolus doses of alfentanyl $(10 \mathrm{mcg} / \mathrm{kg})$. In the regional anesthesia group (group R), patients received peripheral nerve blocks using bupivacaine $0.25 \%$ (volume adjusted according to type of block and patient's weight). Peripheral nerves were identified using peripheral nerve stimulator. During lower limb operations, one arm was used for blood sampling and the other for i.v. fluid infusions. During upper limb operations, contralateral arm was used for i.v. fluid and propofol infusion and the dorsal vein of the foot was used for blood sampling. The tourniquet was applied at a pressure approximately twice the systolic arterial pressure. No blood transfusions were used; the fluid deficits were corrected with ringer lactate during the operation. Using heparin-locked i.v. catheters, sequential venous blood samples were obtained at four time points: before peripheral nerve block and induction of general anesthesia (baseline), $1 \mathrm{~min}$ before tourniquet release (BTR), 5 and $20 \mathrm{~min}$ after tourniquet release (ATR) for the measurements of malondialdehyde (MDA) in plasma and erythrocytes, protein carbonyl (CO) groups concentration, plasma xanthine oxidase (XO) activity and NOx level. Blood samples were centrifuged, plasma was carefully removed and erythrocytes were washed three times in physiological saline. The packed erythrocytes $(0.4 \mathrm{ml})$ were suspended in $1.6 \mathrm{ml}$ phosphate buffer saline pH 7.4 (to obtain $20 \%$ suspension of erythrocytes). The received plasma and erythrocytes were stored at $-20{ }^{\circ} \mathrm{C}$ until assayed.

\section{Estimation of plasma MDA products}

Concentration of MDA in plasma was determined by modified thiobarbituric acid (TBA) method and products of reaction were measured at $535 \mathrm{~nm}$ after adding $\mathrm{FeSO}_{4}$ (Andreeva et al. 1988). The level of MDA was expressed as $\mu \mathrm{mol} / \mathrm{l}$.

\section{Estimation of erythrocyte MDA products}

MDA content of erythrocytes (Er MDA) was estimated as thiobarbituric acid reacting substances by spectrophotometric method at $532 \mathrm{~nm}$ as described by Jain et al. (1990). The results were expressed as nmol $\mathrm{MDA} / \mathrm{ml}$ Er.

Determination of carbonyl groups concentration of oxidatively modified proteins in plasma

The method (Levine et al. 1990) is based on the reaction of carbonyl groups with 2,4-dinitrophenylhydrazine to form a 2,4-dinitrophenylhydrazone reactive 
Table 1. Demographic characteristics of the patients and tourniquet time.

\begin{tabular}{lccc}
\hline & Group S & Group T & Group R \\
\hline Gender ratio $(M / F)$ & $10 / 5$ & $14 / 1^{*}$ & $8 / 7$ \\
UEX/LEX & $9 / 6$ & $12 / 3$ & $9 / 6$ \\
Age $(y r)$ & $12.87 \pm 2.77$ & $11.80 \pm 3.10$ & $14.27 \pm 2.25$ \\
Weight $(\mathrm{kg})$ & $49.20 \pm 17.40$ & $47.80 \pm 19.81$ & $50.47 \pm 11.92$ \\
Height $(\mathrm{cm})$ & $153.07 \pm 18.76$ & $150.73 \pm 19.19$ & $158.80 \pm 11.53$ \\
Tourniquet time (min) & $56.00 \pm 16.28$ & $65.00 \pm 17.11$ & $53.00 \pm 17.13$ \\
\hline
\end{tabular}

* - $p<0.01$ vs. group $\mathrm{R}$

Table 2. Carbonyl groups concentration.

\begin{tabular}{|c|c|c|c|}
\hline $\begin{array}{l}\text { Carbonyl groups } \\
\text { ( } \mu \text { mol/g proteins) }\end{array}$ & Group S & Group T & Group R \\
\hline Basal value & $1.67 \pm 0.25$ & $1.72 \pm 0.30$ & $1.52 \pm 0.23$ \\
\hline $1 \mathrm{~min} B T R$ & $1.47 \pm 0.41$ & $1.93 \pm 0.32^{\mathrm{A}}$ & $1.78 \pm 0.20$ \\
\hline $5 \min A T R$ & $1.63 \pm 0.38$ & $1.74 \pm 0.34$ & $1.54 \pm 0.25$ \\
\hline $20 \min A T R$ & $2.03 \pm 0.20^{*}$ & $1.97 \pm 0.35$ & $1.82 \pm 0.21$ \\
\hline
\end{tabular}

* $-p<0.05$ vs. 1 min BTR

$A-p<0.05$ vs. Group S

carbonyl derivate. The concentration is expressed as $\mu \mathrm{mol} / \mathrm{g}$ proteins.

Determination of nitrites and nitrates (NOx) in plasma

Nitrate is by far the dominating final oxidation product of NO and circulates in levels up to 1000-fold higher than nitrite (Lundberg et al. 2009) thus we measured the cumulative production of these anions (NOx) that we considered to be the marker of $\mathrm{NO}$ production. Plasma NOx level was measured according to Navarro-Gonzales et al. (1998) method with some modifications. The level of NOx was expressed as $\mu \mathrm{mol} / 1$.

\section{Measurement of xantnihe oxidase activity in plasma}

Xanthine oxidase (XO) activity was measured according to the spectrophotometric method of Westerfeld et al. (1959), based on uric acid liberation when xanthine was used as substrate. The activity was expressed as $\mathrm{U} / 1$.

\section{Statistical analysis}

Data were expressed as the mean \pm SD. Differences between the three groups were analyzed with the Kruskal-Wallis test. Significant differences between two groups were analyzed with the Mann Whitney U-test. Changing patterns of plasma MDA, Er MDA, CO groups concentration, $\mathrm{XO}$ activity and NOx level within group were evaluated by Friedman's two-way ANOVA, paired samples Student t-test and nonparametric Wilcoxon signed rank test. Differences were considered significant for $\mathrm{p}<0.05$, using SPSS (Version 15).

\section{Results}

There were no significant differences between the groups in age, weight, height and tourniquet time. There was also no significant between group difference in upper extremity (UEX) and lower extremity (LEX) surgery distribution (Table 1).

The concentration of MDA in plasma decreased nonsignificantly in group $\mathrm{S}$ and group $\mathrm{R}$ before reperfusion (BTR) compared to the baseline. The plasma MDA concentration in group $\mathrm{S}$ (Fig. 1) was significantly higher at $20 \mathrm{~min}$ ATR in comparison with groups $\mathrm{T}$ and $\mathrm{R}$ $(6.78 \pm 0.33 \mu \mathrm{mol} / 1$ vs $4.07 \pm 1.53$ and $3.22 \pm 0.9 \mu \mathrm{mol} / 1$ respectively). The pre-reperfusion (BTR) plasma concentration of MDA in patients receiving propofol (group $\mathrm{T}$ ) seems to be influenced by the tourniquet time which was slightly longer in this group compared to the peripheral nerve block group (group R). In the group $\mathrm{T}$, the most 


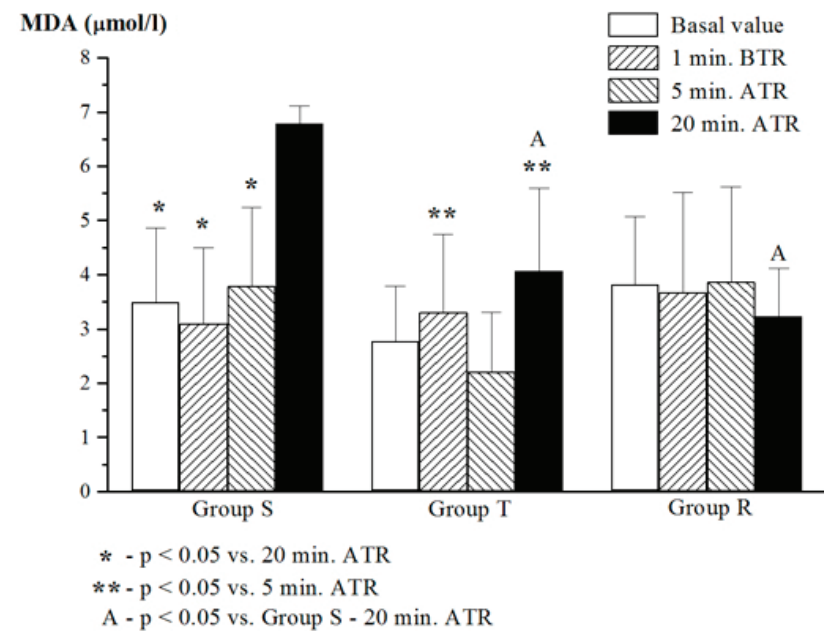

Fig. 1. Concentration of malondialdehyde (MDA) in plasma $(\mu \mathrm{mol} / \mathrm{l})$. Data are expressed as mean \pm SD. Abbrevations: Group $\mathrm{S}$ - general inhalational anesthesia with sevoflurane, Group T total intravenous anesthesia with propofol, Group R - regional anesthesia, BTR - before tourniquet release, ATR - after tourniquet release.

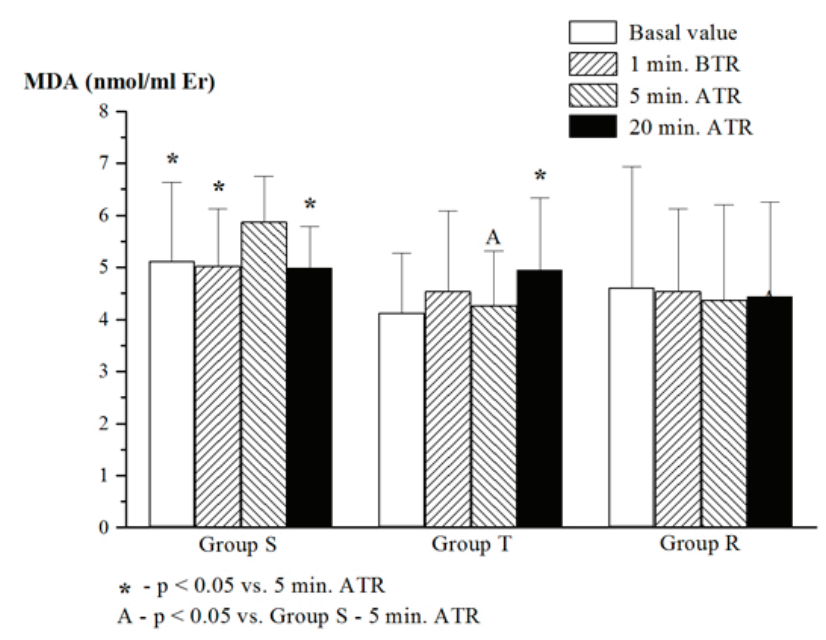

Fig. 2. Concentration of malondialdehyde (MDA) in erythrocytes $(\mathrm{nmol} / \mathrm{mlEr})$. Data are expressed as mean \pm SD. Abbrevations: Group S - general inhalational anesthesia with sevoflurane, Group T - total intravenous anesthesia with propofol, Group R regional anesthesia, BTR - before tourniquet release, ATR - after tourniquet release.

prominent decrease in plasma MDA level was measured 5 min ATR $(2.21 \pm 1.10 \mu \mathrm{mol} / \mathrm{l})$ compared with $1 \mathrm{~min}$ BTR $(3.30 \pm 1.45 \mu \mathrm{mol} / \mathrm{l})$ and $20 \mathrm{~min}$ ATR $(4.07 \pm 1.53 \mu \mathrm{mol} / \mathrm{l})$.

Five minutes after the reperfusion ( 5 min ATR) concentration of MDA in erythrocytes in group $\mathrm{S}$ was significantly higher $(\mathrm{P}<0.05)$ than baseline $(5.11 \pm 1.53 \mathrm{nmol} / \mathrm{mlEr})$, BTR $(5.02 \pm 1.10 \mathrm{nmol} / \mathrm{mlEr})$ and $20 \mathrm{~min}$ ATR values $(4.98 \pm 0.80 \mathrm{nmol} / \mathrm{mlEr})$. There was a significant difference in MDA concentration in erythrocytes (Fig. 2) between groups $\mathrm{S}$ and $\mathrm{T}$ after $5 \mathrm{~min}$ of reperfusion (5.88 $\pm 0.88 \mathrm{vs} 4.27 \pm 1.04 \mathrm{nmol} / \mathrm{mlEr}, \mathrm{p}<0.05)$.

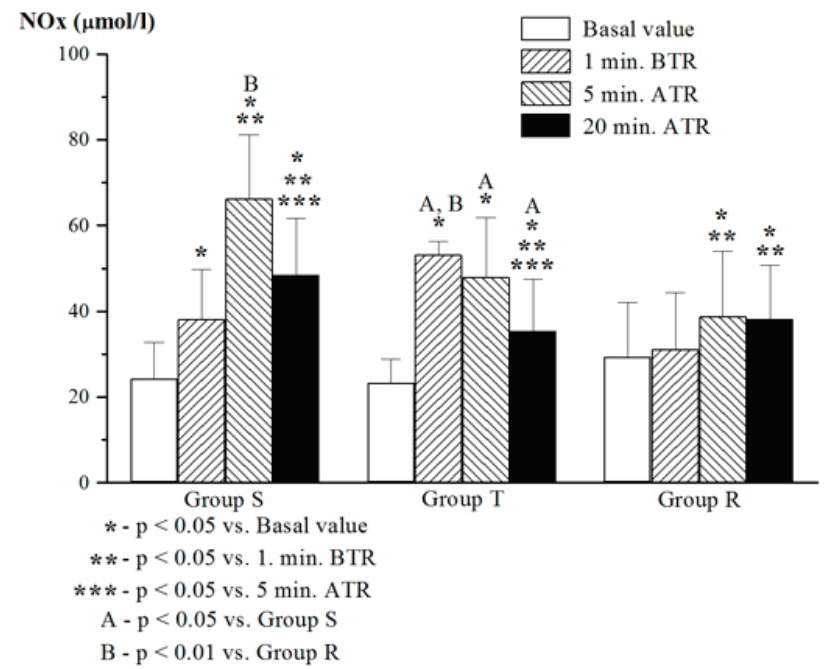

Fig. 3. Plasma NOx level $(\mu \mathrm{mol} / \mathrm{l})$. Data are expressed as mean \pm SD. Abbrevations: Group S - general inhalational anesthesia with sevoflurane, Group $\mathrm{T}$ - total intravenous anesthesia with propofol, Group R - regional anesthesia, BTR - before tourniquet release, ATR - after tourniquet release.

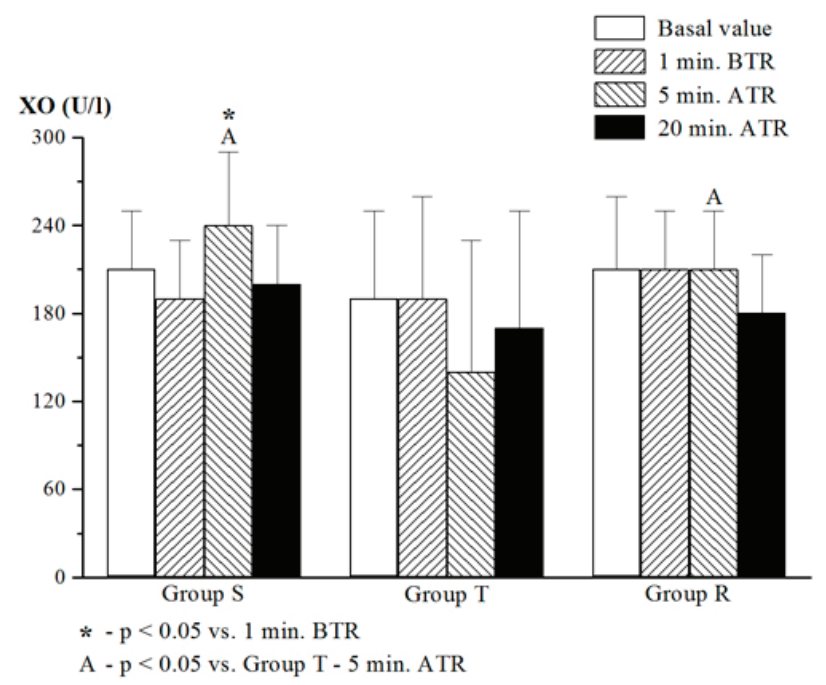

Fig 4. Xanthine oxidase (XO) activity in plasma (U/I). Data are expressed as mean \pm SD. Abbrevations: Group $S$ - general inhalational anesthesia with sevoflurane, Group $\mathrm{T}$ - total intravenous anesthesia with propofol, Group R - regional anesthesia, BTR - before tourniquet release, ATR - after tourniquet release.

Before the tourniquet release (BTR) difference in $\mathrm{CO}$ content (Table 2) was noticed between groups $\mathrm{T}$ and $\mathrm{S}(1.93 \pm 0.32$ vs $1.47 \pm 0.41 \mu \mathrm{mol} / \mathrm{g}$ proteins, $\mathrm{p}<0.05)$. Plasma protein CO content was elevated in group S $20 \mathrm{~min}$ ATR $(2.03 \pm 0.20 \mu \mathrm{mol} / \mathrm{g}$ proteins $)$ in comparison with 1 min BTR concentration $(1.47 \pm 0.41, \mathrm{p}<0.05)$.

Immediately before the start of reperfusion significantly higher level of NOx (Fig. 3) was measured in group $\mathrm{T}(53.11 \pm 13.02 \mu \mathrm{mol} / \mathrm{l})$ in comparison with group $\mathrm{S}(38.14 \pm 11.57 \mu \mathrm{mol} / \mathrm{l}, \mathrm{p}<0.05)$ and group $\mathrm{R}$ 
(31.09 $\pm 13.23 \mu \mathrm{mol} / \mathrm{l}, \mathrm{p}<0.01)$. The plasma NOx value in group $\mathrm{S}$ was significantly higher at $5 \mathrm{~min}$ ATR in comparison with groups $\mathrm{T}$ and $\mathrm{R}(66.25 \pm 14.83 \mu \mathrm{mol} / \mathrm{l}$ vs $47.90 \pm 13.97$ and $38.78 \pm 15.3 \mu \mathrm{mol} / 1$ respectively). There was a significant difference in NOx level between groups $\mathrm{S}$ and $\mathrm{T}$ after $20 \mathrm{~min}$ of reperfusion $(48.45 \pm 13.30 \mathrm{vs}$ $35.39 \pm 12.15 \mu \mathrm{mol} / 1, \mathrm{p}<0.05)$. In the group of patients where peripheral nerve blocks were performed (group R) the increase of NOx after $5(38.78 \pm 15.13 \mu \mathrm{mol} / \mathrm{l})$ and $20 \mathrm{~min}$ of reperfusion $(38.09 \pm 12.62 \mu \mathrm{mol} / \mathrm{l})$ level was noticed compared with the basal $(29.23 \pm 12.89 \mu \mathrm{mol} / \mathrm{l})$ and before tourniquet release level $(31.09 \pm 13.23 \mu \mathrm{mol} / \mathrm{l}$, $\mathrm{p}<0.05)$.

The lowest plasma XO activity (Fig. 4) was noted in group T 5 min ATR compared with groups $\mathrm{S}$ and $\mathrm{R}(140 \pm 90 \mathrm{U} / 1$ vs $240 \pm 50$ and $210 \pm 40 \mathrm{U} / 1$ respectively). Within group variability was significant only in group $S$ $5 \mathrm{~min} \operatorname{ATR}(240 \pm 50 \mathrm{U} / \mathrm{l})$ vs $1 \mathrm{~min}$ BTR $(190 \pm 40 \mathrm{U} / \mathrm{l})$.

\section{Discussion}

Tourniquet application causes metabolic changes that depend on the tourniquet phase (inflation=ischemia, deflation=reperfusion), the time duration of tourniquet inflation, and the anesthetic technique. Although skeletal muscle is thought to be relatively insensitive to the deleterious effects of ischemia and subsequent reperfusion, injury can occur as a result of ischemia such as tourniquet application (Kahraman et al. 1997, Concannon et al. 1992).

The liposoluble anaesthetic drug, propofol (2,6diisopropylphenol), shares a similar structure with phenolic antioxidants like the endogenous alphatocopherol (vitamin E), which has been shown to protect cellular membranes against ROS induced oxidative stress (Vasileiou et al. 2009). The direct effects of propofol on ROS are unknown. As propofol did not enter the cells, the drug would act by scavenging the active oxygen species released in extracellular medium. The commercial form of propofol (Recofol $\AA$ : propofol $10 \mathrm{mg} / \mathrm{ml}$ ) is formulated in intralipid, a lipid vehicle emulsion (10\% soya bean emulsion, egg phosphatides and glycerol). Intralipids could also act directly on cell membranes, and induce structure alterations, leading to a decrease of the ROS release in the extracellular medium (Marthy-Hartert et al. 1998). Numerous experimental studies suggest that volatile anesthetics may protect beyond the heart various tissues and organs subjected to ischemic insult (Minguet et al. 2007). The mechanism by which potent inhalation anesthetics may inhibit free radicals is not known but may involve reducing intracellular calcium concentrations and enhancing availability of interstitial glycolysis metabolites (glucose, lactate and pyruvate) in the skeletal muscle during ischemia and reperfusion (Carles et al. 2008). Regional anesthesia cases (group R) were included in our study for two reasons: to investigate the effects of regional anesthesia on ROS formation and to use this group as a control group for the group of patients receiving sevoflurane (group $\mathrm{S}$ ) and for the group of the patients when anesthesia was maintained with propofol (group T). The pattern of ROS formation from surgical stress is different from that of reperfusion injury. The release of a tourniquet causes an abruptly massive production of ROS and starts oxidative damage (Cheng et al. 2002).

Our results indicate that the most prominent decrease in plasma MDA level in patients who received propofol (group T) was noticed 5 min ATR. This reduction may be explained by the fact that tissues below the tourniquet were saturated with this intravenous anesthetic. Concentration of MDA in plasma in group S 20 min ATR was significantly higher in comparison with groups $\mathrm{T}$ and $\mathrm{R}$ at the same time point. Kotani et al. (1999) found that sevoflurane induced an inflammatory response, whereas the changes in expression of proinflammatory cytokines occurred during exposure to sevoflurane. Turan et al. (2007) observed similar changes in MDA concentration between general, total intravenous and regional anesthesia group in their study. This may be due to effects of both propofol acting as a free radical scavenger, and regional anesthesia, which reduce the stress-inducing hormones adrenaline, noradrenaline and cortisol ( $\mathrm{Ng}$ et al. 1995, Erskine et al. 1994). Moreover, Erturk et al. (2009) concluded that even low-dose infusion of propofol $(2 \mathrm{mg} / \mathrm{kg} / \mathrm{h}$ after a $0.2 \mathrm{mg} / \mathrm{kg}$ bolus) offered protection from tourniquet-induced IR injury in arthroscopic knee surgery under spinal anesthesia. These findings were not confirmed in patients submitted to elective nonischaemianonreperfusion surgery (Braz et al. 2009).

Concentration of MDA in erythrocytes after $20 \mathrm{~min}$ of reperfusion was significantly higher than concentration after $5 \mathrm{~min}$ of reperfusion in a group administering propofol (group $\mathrm{T}$ ). This increase is in accordance with a Cheng et al. (2002) study, in which the highest ROS production measured by chemiluminescence happened at $20 \mathrm{~min}$ after reperfusion. On the contrary, 5 min ATR values in group $\mathrm{S}$ were significantly higher $(\mathrm{P}<0.05)$ than baseline and 20 min ATR values, possibly 
as a result of sudden oxidative burst after tourniquet release caused by high oxygen concentration in inhaled gas mixture $(35 \%)$. The significant difference in erythrocyte MDA between groups $\mathrm{S}$ and $\mathrm{T}$ after $5 \mathrm{~min}$ of reperfusion seems to be in line with this figure reported earlier in the literature that propofol protect erythrocytes against oxidative stress (Murphy et al. 1996). There were no significant differences within the peripheral nerve block patients group (group R), although slight decrease in MDA erythrocyte values was noted at all time points compared to baseline, possibly as a result of bupivacaine property to inhibit surface receptor expression, phagocytosis, and oxidative burst in a time- and concentration-dependent manner (Welters et al. 2001).

Carbonylation of proteins is an irreversible oxidative damage, often leading to a loss of protein function, which is considered a widespread indicator of severe oxidative damage and disease-derived protein dysfunction (Dalle-Donne et al. 2003, Dalle-Donne et al. 2006). In our study, $20 \mathrm{~min}$ after the reperfusion significantly higher increase of plasma $\mathrm{CO}$ concentration was noticed in patients who were anesthetized with sevoflurane. The same pattern was also observed in the patients in whom anesthesia was maintained with propofol or when peripheral blocks were performed but without significant difference. A finding that plasma $\mathrm{CO}$ content was increased at the end of ischemia in propofol group could be explained by the time-dependent increase in carbonilated proteins that occurred parallel with ischemia-induced antioxidant depletion and free radical production (Dalle-Donne et al. 2006).

NO has been implicated in a large number of disease processes (Ignarro 2009), including I/R injury following the restoration of oxygenated blood to previously ischemic muscle. Altered metabolism of NO is implicated in the endothelial dysfunction that forms part of the pathophysiology of ischemia-reperfusion injury. However, NO can demonstrate either protective or cytotoxic effects during reperfusion injury. There appears to be an initial stimulation of NO production in the first $20 \mathrm{~min}$ of ischemia, with a gradual decline through early reperfusion and a second higher peak of NO commencing in the later stages of reperfusion. The absolute levels of $\mathrm{NO}$ in the reperfused tissue and its regulation by the subtle interplay with superoxide and the subsequent production of the highly toxic peroxynitrite anion, are important factors in determining whether $\mathrm{NO}$, in the context of ischemia-reperfusion injury, has damaging or protective effects in the body (Khana et al. 2005). In accordance with the study of Khanna et al. (2005), we also observed an initial stimulation of $\mathrm{NO}$ production in the first $20 \mathrm{~min}$ of ischemia in the group $\mathrm{T}$ that was significantly higher than in groups $\mathrm{S}$ and $\mathrm{R}$. The explanation could lie in the fact that propofol has dual role that could be potentiated just during ischemia and reperfusion. One of the effects of propofol in surgical patients is a decrease in blood pressure. Several theories have been proposed to elucidate the mechanisms involved in the vasoactive property of propofol; one such theory is based on a possible increase in NO production. This was confirmed in the study of Mendez et al. (2003) who reported that changes in both systolic and diastolic blood pressure significantly correlated with changes in the plasma concentration of NOx. The more propofol increased NO production, the larger the reduction in blood pressure was recorded in their surgical patients. After the reperfusion NOx level decreased more in group $\mathrm{T}$ compared with group S. Reperfusion injury is characterized by free radical production and endothelial inflammation. Neutrophils mediate much of the endorgan injury that occurs, requiring P-selectin mediated neutrophil-endothelial adhesion, and this is associated with decreased endothelial nitric oxide production. Propofol has antioxidant properties in vitro which might abrogate this inflammation. Corcoran et al. (2006) concluded that propofol attenuates re-oxygenationinduced endothelial inflammation and NOx production most probably due to an alteration in endothelial nitric oxide synthase (eNOS) or inducible nitric oxide synthase (iNOS). It could be postulated that by this way the inflammation is limited and well know role of propofol to protect endothelial cells in culture against oxidative stress by peroxynitrite scavenging is potentiated. In the group of children who received sevoflurane the highest level were measured $5 \mathrm{~min}$ after the reperfusion, and were significantly increased not only compared with basal and ischemia ( $1 \mathrm{~min}$ before the reperfusion) levels within the same group but they were also significantly higher compared with the levels measured in peripheral nerve block group (Group R) 5 min after the tourniquet release. Obtained result could be a consequence of the fact that sevoflurane increases the release of superoxide anion by the vascular wall (Arriero et al. 2002). Although NO is a peripheral nerve neurotransmitter (Rand et al. 1995), there are no data in the literature about the changes after the peripheral nerve blockade with local anesthetics. The published results are quite contradictory. Toda et al. (2008) reported that local anesthetics decrease the 
production of NO by inhibiting iNOS expression in macrophages and increase NO production in glial cells.

Reoxygenation of previously ischemic tissue leads to deleterious injuries caused by ROS. Xanthineoxidase $(\mathrm{XO})$, during the course of ischemia converted from xanthine dehydrogenase $(\mathrm{XDH})$, represents an important source of superoxide in human vessels (Landmesser et al. 2002, Baudry et al. 2008). Friedl et al. (1990) indicated, for the first time in humans, that ischemia-reperfusion events are associated with the appearance of XO activity and its products in the plasma effluent. They found direct proportionality between the duration of ischemia (tourniquet application) and the level of plasma XO, suggesting a direct link between these two parameters. Surgical trauma, per se, did not lead to a rise in plasma XO in their study. Complete ischemia during the tourniquet application, where collateral circulation is not existed, does not lead to the increase of systemic XO activity before the time of reperfusion (Pouch et al. 1992), which is in accordance with our results. Karg et al. (1997) measured oxidative stress in blood samples in 10 patients undergoing bloodless lower limb surgery under spinal anesthesia with bupivacaine. They found out that $\mathrm{XO}$ activity rose in systemic circulation five minutes after reperfusion, emphasizing the occurrence of oxidative stress in the systemic circulation of patients undergoing bloodless limb surgery. In our study this increase was observed only in patients receiving sevoflurane (Group S) and we didn't notice the same trend in the patients when continuous infusion of propofol (Group $\mathrm{T}$ ) was administered or peripheral nerve blocks performed (Group R). In patients when anesthesia was maintained with continuous infusion of propofol the increase did not occur, probably because of proved property of propofol to reduce XO activity (Lin et al. 2004). Quite the contrary, after 5 and $20 \mathrm{~min}$ after the tourniquet release we observed decrease of XO activity. The most prominent decrease of $\mathrm{XO}$ activity was registered after the peripheral nerve block anesthesia $20 \mathrm{~min}$ after the tourniquet release. The mechanism that could explain this result is complex and represents a consequence of interaction of different oxidant and antioxidant systems, as well as tourniquet application. Nitric oxide reacts as an endogenous suppressor of XO activity (Kinugawa et al. 2005). In many pathophysiological conditions the production of $\mathrm{NO}$ is decreased and NO-mediated suppression of $\mathrm{XO}$ will be reduced, followed by increased production of $\mathrm{O}_{2}^{-}$. At the same time, there is $\mathrm{XO}$ mediated and $\mathrm{O}_{2}{ }^{-}$dependent $\mathrm{NO}$ synthetase activity suppression, so inhibition of XO activity could lead to increase production of NO in vivo (Terada et al. 1997). Sympathetic nerve blockade occurs after central and peripheral nerve block performance. This blockade should lead to reduced level of NO, but after the tourniquet application this condition is not registered. There are certain evidences that XO catalyzes the reduction of nitrates and nitrite to NO under hypoxic conditions (Millar et al. 1998). Five minutes after the tourniquet release in group $\mathrm{R}$ decrease of $\mathrm{XO}$ activity wasn't noticed in comparison to basal values, but after $20 \mathrm{~min}$ this activity was reduced as a result of NOmediated XO suppression.

In conclusion, by decreasing oxidative stress and reducing endothelial dysfunction, TIVA with propofol as well as peripheral nerve block techniques may offer advantages over general anesthesia with sevoflurane during extremity operations at children's age that require application of an ischemic tourniquet.

\section{Conflict of Interest}

There is no conflict of interest.

\section{References}

ANDREEVA IL, KOZEMJAKIN AL, KISKUN AA: Modification of the method of measurement of lipid peroxides in test with thiobarbituric acid. (in Russian) Lab Delo 11: 41-43, 1988.

ARRIERO MM, MUÑOZ ALAMEDA L, LOPEZ-FARRE A, ESCRIBANO BURGOS M, CARRASCO C, MILLÁS I, CELDRÁN A, DE LA PINTA JC: Sevoflurane reduces endothelium-dependent vasorelaxation: role of superoxide anion and endotelin. Can J Anesth 49: 471-476, 2002.

ARNAOUTOGLOU H, VRETZAKIS G, SOULIOTIS D, CMBILI M, GALARIS D, PAPADOPULOS G: The effects of propofol or sevoflurane on free radical production after tourniquet induced ischemia-reperfusion injury during knee arthroplasty. Acta Anaesth Belg 58: 3-6, 2007. 
BAUDRY N, LAEMMEL E, VICAUT E: In vivo reactive oxygen species production induced by ischemia in muscle arterioles of mice: involvement of xanthine oxidase and mitochondria. Am J Physiol Heart Circ Physiol 63: 821-828, 2008.

BRAZ MG, MAGALHAES MR, SALVADORI DM, FERREIRA AL, BRAZ LG, SAKAI E, BRAZ JR: Evaluation of DNA damage and lipoperoxidation of propofol in patients undergoing elective surgery. Eur J Anaesthesiol 26: 654-660, 2009.

CARLES M, DELLAMONICA J, ROUX J, LENA D, LEVRAUT J, PITTET JF, BOILEAU P, RAUCOULES-AIME M.: Sevoflurane but not propofol increases interstitial glycolysis metabolites availability during tourniquetinduced ischemia-reperfusion. Br J Anaesth 100: 29-35, 2008.

CHENG YJ, WANG YP, CHIEN CT, CHEN CF: Small-dose propofol sedation attenuates the formation of reactive oxygen species in tourniquet-induced ischemia-reperfusion injury under spinal anesthesia. Anesth Analg 94: 1617-1620, 2002.

CONCANNON MJ, KESTER CG, WELSH CF, PUCKETT CL: Patterns of free-radical production after tourniquet ischemia: implications for the hand surgeon. Plast Reconstr Surg 89: 846-852, 1992.

CORCORAN TB, O'SHEA A, ENGEL A, SHORTEN GD: The influence of propofol on P-selectin expression and nitric oxide production in re-oxygenated human umbilical vein endothelial cells. Acta Anesth Scand 50: 348 354, 2006.

DALLE-DONNE I, ROSSI R, GIUSTARINI D, MILZANI A, COLOMBO R: Protein carbonyl groups as biomarkers of oxidative stress. Clin Chim Acta 329: 23-38, 2003.

DALLE-DONNE I, ALDINI G, CARINI M, COLOMBO R, ROSSI R: Protein carbonylation, cellular dysfunction, and disease progression. J Cell Mol Med 10: 389-406, 2006.

EATON P, HEARSE DJ, SHATTOCK MJ: Lipid hydroperoxide modification of proteins during myocardial ischemia. Cardiovasc Res 51: 294-303, 2001.

ERSKINE R, JANICKI PK, NEIL G, JAMES MF: Spinal anesthesia but not general anaesthesia enhances neutrophil biocidal activity in hip arthroplasty patients. Can J Anaesth 41: 632-638, 1994.

ERTURK E, CEKIC B, GEZE S, KOSUCU M, COSKUN I, EROGLU A, ULUSOY H, MENTESE A, KARAHAN C, KERIMOGLU S: Comparison of the effect of propofol and $\mathrm{N}$-acetyl cysteine in preventing ischaemiareperfusion injury. Eur J Anaesthesiol 26: 279-284, 2009.

FRIEDL HP, SMITH DJ, TILL GO, THOMPSON PD, LOUIS DS, WARD PA: Ischemia-reperfusion in humans. $A m J$ Pathol 136: 491-495, 1990.

GOURDIN MJ, BREE B, DE KOCK M: The impact of ischaemia-reperfusion on the blood vessel. Eur J Anaesthesiol 26: 537-547, 2009.

IGNARRO LJ: Preface to this special journal issue on nitric oxide chemistry and biology. Arch Pharm Res 32: 1099$1101,2009$.

JAIN SK, LEVINE NS, DUETT J, HOLLIER B: Elevated lipid peroxidation levels in red blood cells of streptozotocintreated diabetic rats. Metabolism 39: 971-975, 1990.

KAHRAMAN S, KILINC K, DAL D, ERDEM K: Propofol attenuates formation of lipid peroxides in tourniquetinduced ischaemia-reperfusion injury. Br J Anaesth 78: 279-281, 1997.

KARG E, NEMETH I, VIRAG T, MESZAROS T, BODA D, PINTER S: Oxidative stress induced by bloodless limb surgery on humans. Eur J Clin Invest 27: 984-991, 1997.

KHANNA A, COWLED PA, FITRIDGE RA: Nitric oxide and skeletal muscle reperfusion injury: current controversies (research review). J Surg Res 128: 98-107, 2005.

KINUGAWA S, HUANG H, WANG Z, KAMINSKI PM, WOLIN MS, HINTZE TH: A defect of neuronal nitric oxide synthase increases xanthine oxidase-derived superoxide anion and attenuates the control of myocardial oxygen consumption by nitric oxide derived from endothelial nitric oxide synthase. Circ Res 96: 355-362, 2005.

KOTANI N, TAKAHASHI S, SESSLER DI, HASHIBA E, KUBOTA T, HASHIMOTO H, MATSUKI A: Volatile anesthetics augment expression of proinflammatory cytokines in rat alveolar macrophages during mechanical ventilation. Anesthesiology 91: 187-197, 1999. 
LANDMESSER U, SPIEKERMANN S, DIKALOV S, TATGE H, WILKE R, KOHLER C, HARRISON DG, HORING B, DREXLER H: Vascularoxidative stress and endothelial dysfunction in patients withchronic heartfailure: role of xanthine-oxidase and extracellular superoxide dismutase. Circulation 106: 3073-3078, 2002.

LEVINE RL, GARLAND D, OLIVER CN, AMICI A, CLIMENT I: Determination of carbonyl content in oxidatively modified proteins. Meth Enzymol 186: 464-478, 1990.

LIN LN, WANG WT, WU JZ, HU ZY, XIE KJ: Protective effect of propofol on liver during ischemia-reperfusion injury in patients undergoing liver surgery. Zhongguo Wei Zhong Bing Ji Jiu Yi Xие 16: 42-44, 2004.

LUNDBERG JO, WEITZBERG E: NO generation from inorganic nitrate and nitrite: role in physiology, nutrition and therapeutics. Arch Pharm Res 32: 1119-1126, 2009.

MARTHY-HARTERT M, DEBY-DUPONT G, HANS P, DEBY C, LAMY M: Protective activity of propofol, Diprivan and intralipid against active oxygen species. Mediators of Inflammation 7: 327-333,1998.

MENDEZ D, DE LA CRUZ JP, ARREBOLA MM, GUERRERO A, GONZALES-CORREA JA, GARCIATEMBOURY E, SANCHEZ DE LA CUESTA F: The effect of propofol on the interaction of platelets with leukocytes and erythrocytes in surgical patients. Anesth Analg 96: 713-719, 2003.

MILLAR TM, STIVENS CR, BENJAMIN N, EISENTHAL R, HARRISON R, BLAKE DR: Xanthine oxidoreductase catalyses the reduction of nitrates and nitrite to nitric oxide under hypoxic conditions. FEBS Lett 427: 225-228, 1998.

MINGUET G, JORIS J, LAMY M: Preconditioning and protection against ischaemia-reperfusion in non-cardiac organs: a place for volatile anaesthetics. Eur J of Anaesthesiol 24: 733-745, 2007.

MURPHY PG, DAVIES MJ, COLUMB MO, STRATFORD N: Effects of propofol and thiopentone on free radical mediated oxidative stress of the erythrocyte. Br J Anaesth 76: 536-543, 1996.

NAVARRO-GONZALES JA, GARCIA-BENAYAS C, ARENOS J: Semiautomated measurement of nitrate in biological fluids. Clin Chem 44: 679-682, 1998.

NG A, TAN SS, LEE HS, CHEW SL: Effect of propofol infusion on the endocrine response to cardiac surgery. Anaesth Intens Care 23: 543-547, 1995.

PUNCH J, REES R, CASHMER B, WILKINS E, SMITH DJ, TILL GO: Xanthine oxidase: its role in the no-reflow phenomenon. Surgery 111: 169-176, 1992.

RAND MJ, LI CG: Nitric oxide as a neurotransmitter in peripheral nerves: nature of transmitter and mechanism of transmission. Annu Rev Physiol 57: 659-682, 1995.

SARICAOGLU F, DAL D, SALMAN AE, DORAL MN, KILINC K, AYPAR U: Ketamine sedation during spinal anesthesia for arthroscopic knee surgery reduced the ischemia-reperfusion injury markers. Anesth Analg 101: 904-909, 2005.

TERADA LS, PIERMATTEI D, SHIBAO GN, MCMANAMAN JL, WRIGHT RM: Hypoxia regulates xanthine dehydrogenase activity at pre- and posttranslational levels. Arch Biochem Biophys 348: 163-168, 1997.

TODA N, TODA H, HATANO Y: Anesthetic modulation of immune reactions mediated by nitric oxide. $J$ Anesth 22: 155-162, 2008.

TSUCHIYA H, UENO T, TANAKA T, MATSUURA N, MIZOGAMI M: Comparative study on determination of antioxidant and membrane activities of propofol and its related compounds. Eur J Pharm Sci 39: 97-102, 2010.

TURAN R, YAGMURDUR H, KAVTZU M, DIKMEN B: Propofol and tourniquet induced ischaemia reperfusion injury in lower extremity operations. Eur J Anaesthesiol 24: 185-189, 2007.

VASILEIOU I, XANTHOS T, KOUDOUNA E, PERREA D, KLONARIS C, KATSARGYRIS A, PAPADIMITRIOU L: Propofol: a review of its non-anaesthetic effects. Eur J Pharmacol 605: 1-8, 2009.

WELTERS ID, MENZEBACH A, LANGEFELD TW, MENZEBACH M, HEMPELMANN G: Inhibitory effects of S$(-)$ and R-(+) bupivacaine on neutrophil function. Acta Anaesthesiol Scand 45: 570-575, 2001.

WESTERFELD W, RICHERT D, HIGGINS E: Further studies with xanthine oxidase inhibitors. J Biol Chem 234: $1887,1959$.

ZAUGG M, LUCCHINETTI E, UECKER M, PASCH T, SCHAUB MC: Anaesthetics and cardiac preconditioning. Part I. Signalling and cytoprotective mechanisms. Br J Anaesth 91: 551-565, 2003. 